\title{
Phenotype Analysis of Retinal Dystrophies in Light of the Underlying Genetic Defects: Application to Cone and Cone-Rod Dystrophies
}

\author{
Elise Boulanger-Scemama ${ }^{1,2}$, Saddek Mohand-Saïd ${ }^{1,3}$, Said El Shamieh ${ }^{1,4}{ }^{(0)}$, \\ Vanessa Démontant ${ }^{1}$, Christel Condroyer ${ }^{1}$, Aline Antonio ${ }^{1,3}$, Christelle Michiels ${ }^{1}$, \\ Fiona Boyard ${ }^{1}$, Jean-Paul Saraiva ${ }^{5}$, Mélanie Letexier ${ }^{5}$, José-Alain Sahel 1,2,3,6,7, \\ Christina Zeitz ${ }^{1(D)}$ and Isabelle Audo 1,3,8,*(D) \\ 1 Institut de la Vision, Sorbonne Universités, UPMC Univ Paris 06, INSERM, CNRS, 17 rue Moreau, \\ 75012 Paris, France; eboulanger@for.paris (E.B.-S.); saddekms@gmail.com (S.M.-S.); \\ said.shamieh@gmail.com (S.E.S.); vanessa.demontant@inserm.fr (V.D.); christel.condroyer@inserm.fr (C.C.); \\ aline.antonio@inserm.fr (A.A.); christelle.michiels@inserm.fr (C.M.); fiona.boyard@gmail.com (F.B.); \\ j.sahel@gmail.com (J.-A.S.); christina.zeitz@inserm.fr (C.Z.) \\ 2 Fondation Ophtalmologique Adolphe de Rothschild, 75012 Paris, France \\ 3 CHNO des Quinze-Vingts, DHU Sight Restore, INSERM-DHOS CIC1423, 28 rue de Charenton, \\ 75012 Paris, France \\ 4 Department of Medical Laboratory Sciences, Faculty of Health Sciences, Beirut Arab University, \\ Beirut, Lebanon \\ 5 IntegraGen SA, Genopole CAMPUS 1 bat G8 FR, 91030 Evry, France; \\ jean-paul.saraiva@integragen.com (J.-P.S.); melanie.letexier@integragen.com (M.L.) \\ 6 Académie des Sciences-Institut de France, 75006 Paris, France \\ 7 Department of Ophthalmology, The University of Pittsburgh School of Medicine, Pittsburg, PA 15213, USA \\ 8 University College London Institute of Ophthalmology, 11-43 Bath Street, London EC1V 9EL, UK \\ * Correspondence: isabelle.audo@inserm.fr; Tel.: +33-1-53-46-25-42 or +33-1-53-46-25-40
}

Received: 28 August 2019; Accepted: 25 September 2019; Published: 30 September 2019

\begin{abstract}
Phenotypes observed in a large cohort of patients with cone and cone-rod dystrophies (COD/CORDs) are described based on multimodal retinal imaging features in order to help in analyzing massive next-generation sequencing data. Structural abnormalities of 58 subjects with molecular diagnosis of COD/CORDs were analyzed through specific retinal imaging including spectral-domain optical coherence tomography (SD-OCT) and fundus autofluorescence (BAF/IRAF). Findings were analyzed with the underlying genetic defects. A ring of increased autofluorescence was mainly observed in patients with CRX and GUCY2D mutations (33\% and 22\% of cases respectively). "Speckled" autofluorescence was observed with mutations in three different genes (ABCA4 64\%; C2Orf71 and PRPH2, 18\% each). Peripapillary sparing was only found in association with mutations in $A B C A 4$, although only present in $40 \%$ of such genotypes. Regarding SD-OCT, specific outer retinal abnormalities were more commonly observed in particular genotypes: focal retrofoveal interruption and GUCY2D mutations (50\%), foveal sparing and CRX mutations (50\%), and outer retinal atrophy associated with hyperreflective dots and $A B C A 4$ mutations (69\%). This study outlines the phenotypic heterogeneity of COD/CORDs hampering statistical correlations. A larger study correlating retinal imaging with genetic results is necessary to identify specific clinical features that may help in selecting pathogenic variants generated by high-throughput sequencing.
\end{abstract}

Keywords: cone-rod dystrophy; next-generation sequencing 


\section{Introduction}

Cone and cone-rod dystrophies (COD/CORDs) refer to a heterogeneous group of inherited retinal disorders (IRDs), characterized predominantly by cone impairment. They are the most common cause of hereditary cone dysfunction, with a prevalence of 1:40,000 [1]. They are characterized by progressive central vision loss, photophobia, and color vision abnormalities in childhood or early adulthood. In most cases, with a variable onset in the course of the disease, patients develop secondary rod system involvement that leads to night blindness and peripheral visual field constriction [1]. On fundoscopy, the macular appearance ranges from normal to bull's eye maculopathy, or more severe macular atrophy with possible pigmentary changes in the periphery in the case of rod photoreceptor involvement [2]. Full-field electroretinogram (ERG) examination is key in diagnosis and reveals both cone and rod impairment with predominant cone dysfunction. In advanced cases, ERG responses may be undetectable, making the distinction between CORD and severe rod-cone dystrophy (RCD) difficult, and somewhat artificial, in these cases. Progressive COD/CORDs need to be distinguished from cone dysfunction syndromes, which are stationary and congenital with normal rod function [3]. COD/CORDs often present as an isolated disease, but they can also be part of a syndrome as in Bardet-Biedl or Jalili syndromes or spinocerebellar ataxia $7[1,4,5]$.

The genetic basis of COD/CORDs is highly heterogeneous, with significant overlap with other IRD-associated gene defects. All modes of inheritance have been reported: autosomal recessive (ar), autosomal dominant (ad), or X-linked (xl). To date, mutations in 33 genes have been implicated in COD/CORDs (https://sph.uth.edu/retnet/ September 2017). Mutations in ABCA4 (ATP-binding cassette, sub-family A, member 4) [6,7], GUCY2D (guanylate cyclase 2D) [8,9], and RPGR (retinitis pigmentosa GTPase regulator) $[10,11]$ are major causes of ar, ad, and xl COD/CORDs, respectively.

Because of this high phenotypic and genetic heterogeneity, patient management and genetic counseling are currently challenging for clinicians who diagnose CODs and CORDs. The application of high-throughput sequencing tools for genetic diagnosis increases the yield to identify the underlying genetic defect(s), but filtering and interpretation of massive data are necessary to identify causative gene defects. The purpose of this cross-sectional study was to conduct a phenotyping analysis of a large cohort of COD/CORDS patients, previously genetically investigated by a targeted next-generation sequencing (NGS) panel, [12] using retinal imaging; therefore, we attempted to identify schematic phenotype/genotype associations in order to help in interpreting massive data generated from NGS.

\section{Results}

\subsection{Clinical and Genetic Characteristics}

Baseline clinical characteristics of all probands are summarized in Table 1.

Table 1. Clinical characteristics of the cohort ( $\mathrm{N}=58$ patients).

\begin{tabular}{lcc}
\hline $\begin{array}{l}\text { Age at the onset of symptoms (decreased central vision } \\
\text { and/or photophobia) (median (min-max), years) }\end{array}$ & $10(1-55)$ & $(\mathrm{N}=36) *$ \\
Age at clinical exam (average (SD, min-max), years) & $35(5,7-78)$ & \\
Mode of inheritance & & $(\mathrm{N}=58)$ \\
$\quad$ Autosomal recessive, $\mathrm{n}(\%)$ & $11(19)$ & \\
$\quad$ Autosomal dominant, n (\%) & $25(43)$ & \\
Sporadic, n (\%) & $14(24)$ & $(\mathrm{N}=58)$ \\
Sex & $20: 400(20: 125)$ & $(\mathrm{N}=53)$ \\
$\quad$ Male, n (\%) & $1.3(0.8)$ & \\
BCVA (average (SD), ETDRS) & $-2.5(3.5)$ & $(\mathrm{N}=49)$ \\
BCVA (average (SD), LogMar) & \\
Spherical equivalent (average (SD), Diopters) &
\end{tabular}

DS: standard deviation; BCVA: best corrected visual acuity; ETDRS: Early Treatment Diabetic Retinopathy Study. * Data were not collected for the 22 other patients. 
Sporadic, ar, and ad (43\%, 38\%, and 19\%, respectively) cases were included in the study. As previously reported [12], applying a targeted NGS approach, pathogenic or likely pathogenic mutations were identified in 23 genes ( 12 known COD/CORDs-associated genes and 11 other retinal disease associated genes) (Table 2, detailed genetic results and co-segregation analysis are available in a previous article [12]). Mutations in ABCA4 (ATP-binding cassette, sub-family A, member 4) and GUCY2D (guanylate cyclase 2D) were reported in $36 \%$ and $30 \%$ of the individuals showing ar and ad modes of inheritance, respectively, making them the major defective genes in our cohort.

Table 2. Summary of 58 patients carrying pathogenic and likely pathogenic mutations in known CCRD genes or other retinal disease genes.

\begin{tabular}{|c|c|c|c|c|c|c|c|}
\hline ID & Type & Gene & Allele Status & & cDNA & Protein & References \\
\hline \multicolumn{8}{|c|}{ Known CCRD genes } \\
\hline CIC00137 & sporadic & $A B C A 4$ & Ho & 47 & c. $6394 \mathrm{G}>\mathrm{A}$ & p.(E2132K) & $\begin{array}{c}\text { (Boulanger-Scemama } \\
\text { et al. 2015) }\end{array}$ \\
\hline \multirow[t]{2}{*}{ CIC00162 } & $\mathrm{Ar}$ & $A B C A 4$ & Het & 31 & c.4546_4547del & p.(Q1516Afs*38) & $\begin{array}{c}\text { (Boulanger-Scemama } \\
\text { et al. 2015) }\end{array}$ \\
\hline & & $A B C A 4$ & Het & 16 & c. $2463 \mathrm{G}>\mathrm{A}$ & p. $\left(\mathrm{W} 821^{*}\right)$ & $\begin{array}{c}\text { (Boulanger-Scemama } \\
\text { et al. 2015) }\end{array}$ \\
\hline CIC00765 & $\mathrm{Ar}$ & $A B C A 4$ & Ho & 47 & c. $6445 \mathrm{C}>\mathrm{T}$ & p.(R2149*) & $\begin{array}{c}\text { (Lewis et al. 1999) } \\
\text { (rs61750654) }\end{array}$ \\
\hline CIC03436 & $\mathrm{Ar}$ & $A B C A 4$ & Ho & 42 & c.5892del & p. $($ G1965Efs*9) & [1] \\
\hline \multirow[t]{2}{*}{ CIC04412 } & sporadic & $A B C 4 A$ & Het & 34 & c. $4793 \mathrm{C}>\mathrm{A}$ & p.(A1598D) & $\begin{array}{c}\text { (Maugeri et al. 2000) } \\
\text { (rs61750155) }\end{array}$ \\
\hline & & $A B C A 4$ & Het & 28 & c. $4234 \mathrm{C}>\mathrm{T}$ & p.(Q1412*) & $\begin{array}{l}\text { (Maugeri et al. 2000) } \\
\text { (rs61750137) }\end{array}$ \\
\hline CIC04645 & $\mathrm{Ar}$ & $A B C A 4$ & Ho & 13 & c. $1924 \mathrm{~T}>\mathrm{C}$ & p.(F642L) & $\begin{array}{l}\text { (Boulanger-Scemama } \\
\text { et al. 2015), but } \\
\text { c.1924T > A p.F642I in } \\
\text { (Jin et al. 2014) }\end{array}$ \\
\hline CIC05087 & sporadic & $A B C A 4$ & Ho & $\begin{array}{c}\text { IVS } \\
11\end{array}$ & c. $1554+1 G>C$ & r.(spl?) & $\begin{array}{c}\text { (Boulanger-Scemama } \\
\text { et al. 2015) }\end{array}$ \\
\hline CIC05853 & sporadic & $A B C 4 A$ & Ho & 22 & c. $3259 \mathrm{G}>\mathrm{A}$ & p.(E1087K) & $\begin{array}{c}\text { (Allikmets et al. 1997) } \\
\text { (rs61751398) }\end{array}$ \\
\hline CIC05854 & $\mathrm{Ar}$ & $A B C 4 A$ & Ho & 35 & c. $4919 \mathrm{G}>\mathrm{A}$ & p.(R1640Q) & $\begin{array}{c}\text { (Simonelli et al. 2000) } \\
\text { (rs61751403) }\end{array}$ \\
\hline \multirow[t]{2}{*}{ CIC05987 } & $\mathrm{Ar}$ & $A B C 4 A$ & Het & 22 & c. $3295 \mathrm{~T}>\mathrm{C}$ & p.(S1099P) & $\begin{array}{c}\text { (Fumagalli et al. 2001) } \\
\text { (rs61750119) }\end{array}$ \\
\hline & & $A B C 4 A$ & Het & 4 & c.327dup & p.(Q110Sfs*51) & $\begin{array}{c}\text { (Boulanger-Scemama } \\
\text { et al. 2015) } \\
\text { (rs 61748531) }\end{array}$ \\
\hline \multirow[t]{3}{*}{ CIC05989 } & sporadic & $A B C 4 A$ & Het & 34 & c. $4837 \mathrm{G}>\mathrm{A}$ & p.(D1613N) & $\begin{array}{c}\text { (Boulanger-Scemama } \\
\text { et al. 2015) }\end{array}$ \\
\hline & & $A B C 4 A$ & Het & 10 & c.1302del & p.(Q437Rfs*12) & $\begin{array}{l}\text { (Boulanger-Scemama } \\
\text { et al. 2015) }\end{array}$ \\
\hline & & $A B C A 4$ & Het & 38 & c. $5318 \mathrm{C}>\mathrm{T}$ & p.(A1773V) & (Stenirri et al. 2008) \\
\hline \multirow[t]{3}{*}{ CIC06170 } & sporadic & $A B C 4 A$ & Het & 44 & c. $6089 \mathrm{G}>\mathrm{A}$ & p.(R2030Q) & $\begin{array}{l}\text { (Lewis et al. 1999) } \\
\text { (rs61750641) }\end{array}$ \\
\hline & & $A B C 4 A$ & Het & $\begin{array}{l}\text { IVS } \\
24\end{array}$ & c. $3607+3 \mathrm{~A}>\mathrm{T}$ & r.(spl?) & $\begin{array}{c}\text { (Boulanger-Scemama } \\
\text { et al.2015) }\end{array}$ \\
\hline & & $A B C A 4$ & Het & 14 & c. $2034 \mathrm{G}>\mathrm{T}$ & p.(K678N) & (Huang et al. 2014) \\
\hline \multirow[t]{2}{*}{ CIC06694 } & sporadic & $A B C 4 A$ & Het & IVS36 & c. $5196+1 G>A$ & r.(spl?) & $\begin{array}{l}\text { (Kitiratschky et al. } \\
\text { 2008) }\end{array}$ \\
\hline & & $A B C 4 A$ & Het & 22 & c. $3322 \mathrm{C}>\mathrm{T}$ & p.(R1108C) & (Briggs et al. 2001) \\
\hline CIC06735 & $\mathrm{Ar}$ & $A B C 4 A$ & Ho & 42 & c.5892del & p.(G1965Efs*9) & [1] \\
\hline CIC06913 & $\mathrm{Ar}$ & $A B C A 4$ & Ho & 21 & c. $3056 \mathrm{C}>\mathrm{T}$ & p.(T1019M) & $\begin{array}{l}\text { (Rozet et al. 1998) } \\
\quad(\text { rs201855602) }\end{array}$ \\
\hline CIC07563 & sporadic & SEMA4A & Ho & 3 & c. $241 \mathrm{C}>\mathrm{T}$ & $\mathrm{p} .\left(\mathrm{R} 81^{*}\right)$ & $\begin{array}{c}\text { (Boulanger-Scemama } \\
\text { et al. 2015) }\end{array}$ \\
\hline
\end{tabular}


Table 2. Cont.

\begin{tabular}{|c|c|c|c|c|c|c|c|}
\hline ID & Type & Gene & Allele Status & & cDNA & Protein & References \\
\hline \multicolumn{8}{|c|}{ Known CCRD genes } \\
\hline CIC00324 & $\mathrm{Ad}$ & GUCY2D & Het & 13 & c. $2512 C>T$ & p.(R838C) & (Kelsell et al. 1998) \\
\hline CIC04239 & $\mathrm{Ar}$ & CDHR1 & Ho & 9 & c. $838 \mathrm{C}>\mathrm{T}$ & p. $\left(\mathrm{R} 280^{*}\right)$ & $\begin{array}{c}\text { (Boulanger-Scemama } \\
\text { et al. 2015) }\end{array}$ \\
\hline CIC06568 & $\mathrm{Ar}$ & CERKL & Ho & 8 & c. $1090 \mathrm{C}>\mathrm{T}$ & p.(R364*) & $\begin{array}{c}\text { Thesis (Sergouniotis } P \\
\text { 2012) [2] }\end{array}$ \\
\hline CIC07299 & sporadic & PDE6C & Ho & 2 & c.542del & p.(A181Efs*13) & $\begin{array}{c}\text { (Boulanger-Scemama } \\
\text { et al. 2015) }\end{array}$ \\
\hline CIC05563 & $\mathrm{Ad}$ & $S E M A 4 A$ & Het & 4 & c. $302 \mathrm{~T}>\mathrm{C}$ & p.(I101T) & $\begin{array}{c}\text { (Boulanger-Scemama } \\
\text { et al. 2015) } \\
\text { (rs149652495) } \\
\text { (rs61750172) }\end{array}$ \\
\hline CIC03249 & Ad & GUCY2D & Het & 13 & c. $2512 \mathrm{C}>\mathrm{T}$ & p.(R838C) & $\begin{array}{l}\text { (Kelsell et al. 1998) } \\
\text { (rs61750172) }\end{array}$ \\
\hline CIC04347 & $\mathrm{Ad}$ & GUCY2D & Het & 13 & c. $2512 \mathrm{C}>\mathrm{T}$ & p.(R838C) & $\begin{array}{l}\text { (Kelsell et al. 1998) } \\
\text { (rs61750172) }\end{array}$ \\
\hline CIC04918 & $\mathrm{Ad}$ & GUCY2D & Het & 13 & c. $2512 \mathrm{C}>\mathrm{T}$ & p.(R838C) & $\begin{array}{l}\text { (Kelsell et al. 1998) } \\
\text { (rs61750172) }\end{array}$ \\
\hline CIC00597 & sporadic & GUCY2D & Het & 14 & c. $2747 \mathrm{~T}>\mathrm{C}$ & p.(I916T) & $\begin{array}{c}\text { (De Castro-Miró et al. } \\
2014)\end{array}$ \\
\hline CIC06352 & sporadic & GUCA1A & Het & 3 & c. $149 \mathrm{C}>\mathrm{T}$ & p.(P50L) & $\begin{array}{c}\text { (Downes et al. 2001) } \\
\quad(\mathrm{rs} 104893968)\end{array}$ \\
\hline CIC06757 & Ad & PRPH2 & Het & 1 & c. $514 \mathrm{C}>\mathrm{T}$ & p.(R172W) & $\begin{array}{l}\text { (Wells et al. 1993) } \\
\quad(\text { rs61755792) }\end{array}$ \\
\hline CIC03621 & $\mathrm{Ad}$ & PRPH2 & Het & 1 & c.1-c581+?del & - & $\begin{array}{c}\text { (Boulanger-Scemama } \\
\text { et al. 2015) }\end{array}$ \\
\hline CIC00535 & $\mathrm{Ad}$ & PROM1 & Het & 10 & c. $1117 \mathrm{C}>\mathrm{T}$ & p.(R373C) & $\begin{array}{c}\text { (Michaelides et al. } \\
\text { 2006) } \\
\text { (rs137853006) }\end{array}$ \\
\hline CIC01196 & sporadic & PROM1 & Ho & 12 & c.1354dup & p.(Y452Lfs*13) & (Pras et al. 2009) \\
\hline \multirow[t]{2}{*}{ CIC07188 } & sporadic & PROM1 & Het & 12 & c.1354dup & p.(Y452Lfs*13) & (Pras et al. 2009) \\
\hline & & PROM1 & Het & $\begin{array}{c}\text { IVS } \\
12\end{array}$ & c. $1454+2 \mathrm{~T}>\mathrm{C}$ & r.(spl?) & $\begin{array}{l}\text { (Boulanger-Scemama } \\
\text { et al. 2015) }\end{array}$ \\
\hline CIC07045 & sporadic & PROM1 & Ho & $\begin{array}{c}\text { IVS } \\
17\end{array}$ & c. $1984-1 G>T$ & r.(spl?) & $\begin{array}{c}\text { (Boulanger-Scemama } \\
\text { et al. 2015) } \\
\text { (rs373680665) }\end{array}$ \\
\hline CIC06642 & Ad & PROM1 & Het & 1 & c.7dup & p. $\left(\mathrm{L} 3 \mathrm{Pfs}^{*} 28\right)$ & $\begin{array}{c}\text { (Boulanger-Scemama } \\
\text { et al. 2015) }\end{array}$ \\
\hline CIC04965 & $\mathrm{Ad}$ & $C R X$ & Het & 4 & c.608_609del & p.(S203Ffs*32) & $\begin{array}{c}\text { (Boulanger-Scemama } \\
\text { et al. 2015) }\end{array}$ \\
\hline CIC03241 & sporadic & $C R X$ & Het & 4 & c.564dup & p.(A189Rfs*47) & $\begin{array}{l}\text { Not clear if same } \\
\text { mutation as in (Stone } \\
\text { 2007) }\end{array}$ \\
\hline СIC3750 & sporadic & $C R X$ & Het & 3 & c. $121 \mathrm{C}>\mathrm{T}$ & p.(R41W) & $\begin{array}{l}\text { (Swain et al. 1997) } \\
\text { (rs104894672) }\end{array}$ \\
\hline CIC05218 & $\mathrm{Ar}$ & PDE6C & Ho & $\begin{array}{l}\text { IVS } \\
10\end{array}$ & c. $1413+3 \mathrm{~A}>\mathrm{T}$ & r.(spl?) & $\begin{array}{c}\text { (Boulanger-Scemama } \\
\text { et al. 2015) }\end{array}$ \\
\hline \multirow[t]{2}{*}{ CIC02712 } & sporadic & PDE6C & Het & 10 & c. $1325 \mathrm{~T}>\mathrm{A}$ & p.(M442K) & $\begin{array}{c}\text { (Boulanger-Scemama } \\
\text { et al. 2015) }\end{array}$ \\
\hline & & PDE6C & Het & 10 & c. $1375 C>G$ & p.(Q459E) & $\begin{array}{c}\text { (Boulanger-Scemama } \\
\text { et al. 2015) }\end{array}$ \\
\hline CIC06321 & sporadic & RPGRIP1 & Ho & 14 & c. $2021 \mathrm{C}>\mathrm{A}$ & p. $(\mathrm{P} 674 \mathrm{H})$ & $\begin{array}{c}\text { (Boulanger-Scemama } \\
\text { et al. 2015) }\end{array}$ \\
\hline CIC00190 & sporadic & AIPL1 & Het & 5 & c. $769 \mathrm{C}>\mathrm{T}$ & p.(L257F) & $\begin{array}{c}\text { (Boulanger-Scemama } \\
\text { et al. 2015) }\end{array}$ \\
\hline \multirow{3}{*}{ CIC04945 } & & AIPL1 & Het & 5 & c. $767 \mathrm{~T}>\mathrm{G}$ & p.(I256S) & $\begin{array}{c}\text { (Boulanger-Scemama } \\
\text { et al. 2015) }\end{array}$ \\
\hline & sporadic & PROM1 & Het & 23 & c. $2383 \mathrm{~T}>\mathrm{C}$ & p.(W795R) & $\begin{array}{c}\text { (Boulanger-Scemama } \\
\text { et al. 2015) }\end{array}$ \\
\hline & & PROM1 & Het & $\begin{array}{l}\text { IVS } \\
13\end{array}$ & c. $1579-1 \mathrm{G}>\mathrm{C}$ & r.(spl?) & $\begin{array}{c}\text { (Boulanger-Scemama } \\
\text { et al. 2015) }\end{array}$ \\
\hline CIC07569 & sporadic & $C R X$ & Het & $\begin{array}{c}\text { IVS } \\
3\end{array}$ & c. $252+1 G>A$ & r.(spl?) & $\begin{array}{c}\text { (Boulanger-Scemama } \\
\text { et al. 2015) }\end{array}$ \\
\hline
\end{tabular}


Table 2. Cont.

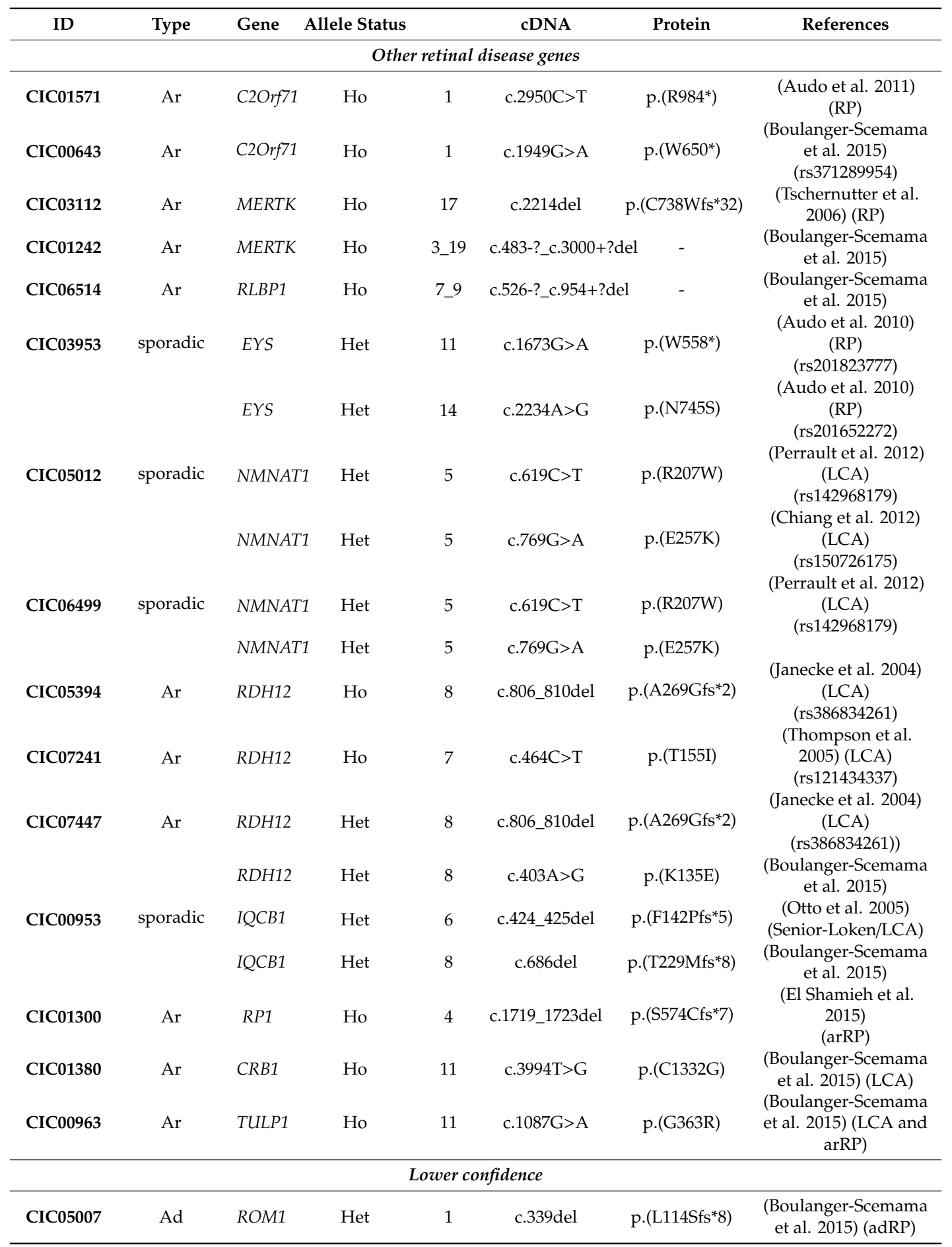

Ar: autosomal recessive; Ad: autosomal dominant; RP: retinitis pigmentosa; MD: macular dystrophy; LCA: Leber congenital amaurosis; [1] personal communication B. Puech. [2] Sergouniotis P. (2012). Genotype and phenotypic heterogeneity in autosomal recessive retinal disease. Ph.D. Thesis. Institute of Ophthalmology, University College London, United Kingdom.

\subsection{Retinophotography}

The fundus revealed abnormalities either limited to the macular area $(64.5 \%)$ or extended to the peripheral retina (37.5\%). Four distinct fundus patterns were identified: macular RPE alterations (21\%), "bull's eye maculopathy" with perifoveal atrophy sparing the fovea (9\%), macular atrophy (34\%), and extensive retinal atrophy $(36 \%)$. (Figure 1 ) 

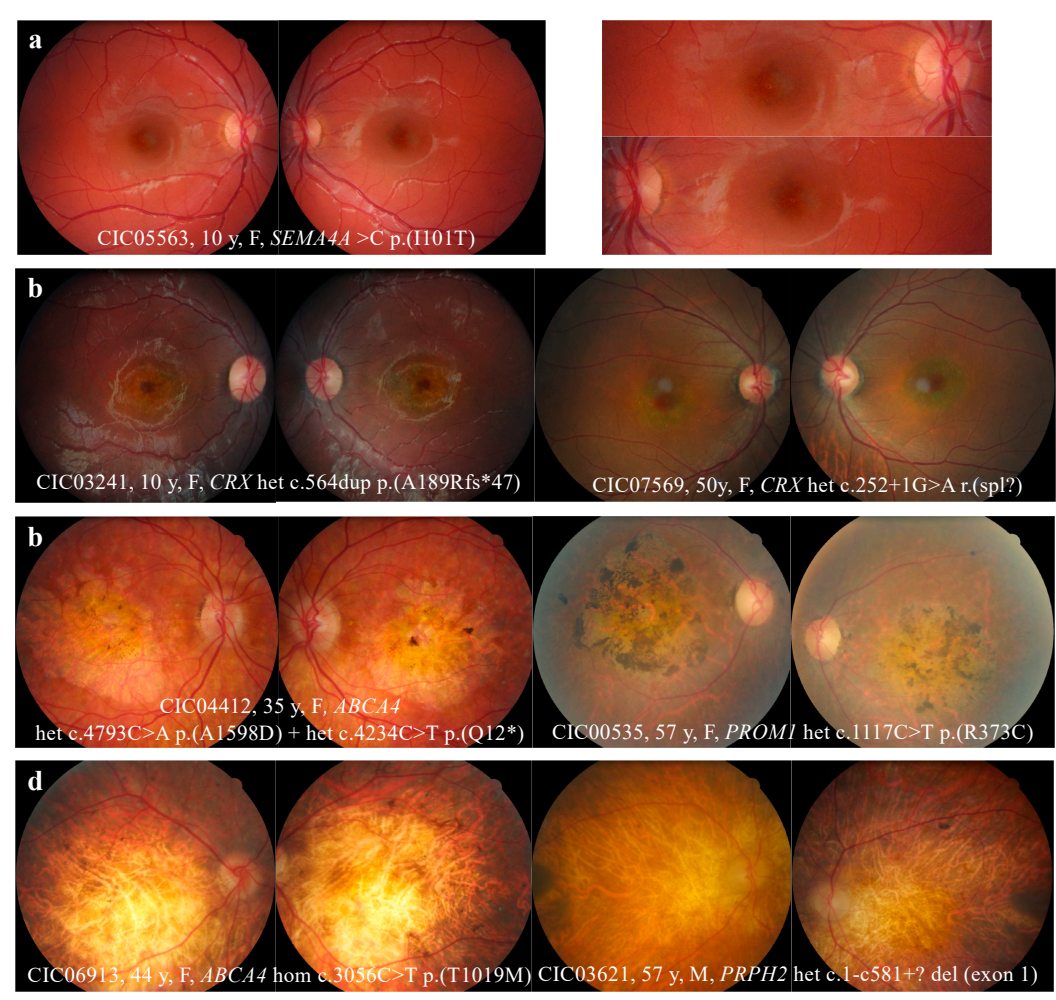

Figure 1. Fundus abnormalities observed in cone and cone-rod dystrophy (COD/CORD) patients of the cohort. (a) Macular retinal pigment epithelium (RPE) alterations. (b) "Bull's eye maculopathy" defined by perifoveal atrophy sparing the fovea. Note the temporal pallor of the optic disc for patient CIC03241, a clinical feature known to be associated with CODs. (c) Retinal and RPE atrophy limited to the macular region. Note the pigmented aspect above the macular atrophy, sharply marked in patient CIC00535. (d) Extensive retinal atrophy from the macula to the peripheral retina. Note the optic disk pallor, narrowing vascular network, and peripheral osteoblasts evoking the differential diagnosis of retinitis pigmentosa.

\section{3. $S D-O C T$}

Table 3 shows abnormalities observed in SD-OCT, illustrated by Figure 2.

Table 3. Spectral-domain optical coherence tomography (SD-OCT) abnormalities ( $\mathrm{N}=49$ patients).

\begin{tabular}{lc}
\hline & $\mathbf{n}(\mathbf{\%})$ \\
\hline OUTER RETINA & $3(6)$ \\
EZ irregularities & \\
Hyperreflective layers disruption (foveal/beyond the fovea) & $39(80) / 27(55)$ \\
ELM & $46(94) / 30(61)$ \\
EZ & $49(100) / 42(86)$ \\
IZ & $0(0) / 0(0)$ \\
RPE & $3(6)$ \\
Hyporeflective foveal cavitation & $6(12)$ \\
Foveal sparing & $14(28)$ \\
Hyper-reflective deposits above the RPE & $1(2)$ \\
Outer retinal tubulations & $36(73)$ \\
Outer nuclear layer atrophy in the macular region & $20(41)$ \\
Diffuse outer retinal atrophy beyond the vascular arcades & \\
INNER RETINA & $2(4)$ \\
Hyporeflective macular cysts & \\
\hline
\end{tabular}

ELM: external limiting membrane; EZ: ellipsoid zone; IZ: interdigitation zone; RPE: retinal pigment epithelium. 

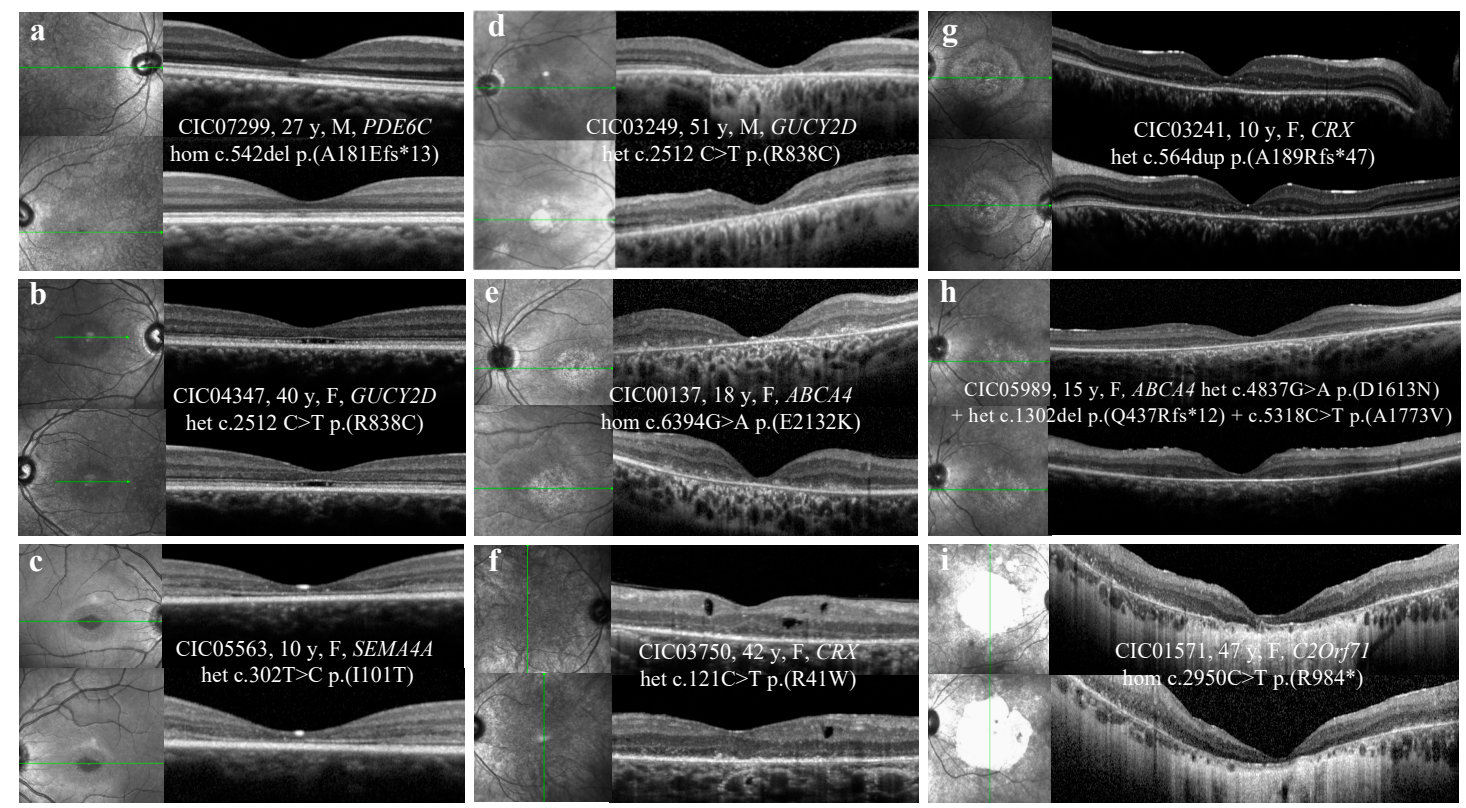

Figure 2. SD-OCT abnormalities observed in COD/CORDs patients of the cohort. (a) Abnormalities limited to the foveal region, irregular aspect or disruption of the ellipsoid zone (EZ) and the interdigitation zone (IZ). (b) Hyporeflective foveal cavitation. EZ and IZ are disrupted, while ELM and RPE layers are respected. (c) Perifoveal and foveal abnormalities. EZ and IZ are disrupted, while ELM is respected. (d) Outer retinal atrophy of the foveal and perifoveal regions. (e) Hyper-reflective deposits above the RPE in the foveal and perifoveal regions. (f) Hyporeflective cysts at the level of the outer and inner nuclear layers without macular edema. (g) Foveal sparing of the outer hyper-reflective layers; visual acuity is quite preserved for this patient (20/63 OD, 20/80 OG). (h) Outer retinal atrophy of the macular region. (i) Extensive chorioretinal atrophy with retinal thinning of the foveal region and choroidal hyperreflectivity by window defect. SD-OCT: spectral-domain optical coherence tomography; COD/CORDs: cone and cone-rod dystrophy; EZ: ellipsoid zone; IZ: interdigitation zone; ELM: external limiting membrane; RPE: retinal pigment epithelium.

ELM, EZ, and IZ were disrupted in the foveal/perifoveal region in $80 \%, 94 \%$, and $100 \%$ of cases, respectively. Foveal sparing of the outer retinal layers was observed in 6 patients (12\%), whereas hyporeflective foveal cavitation was observed in 3 patients (6\%). Hyper-reflective deposits above the RPE were observed in $28 \%$ of cases. Macular outer nuclear layer atrophy was present in $73 \%$ of patients. Among these, $41 \%$ revealed extensive atrophy beyond the vascular arcades.

In 2 cases, SD-OCT revealed hyporeflective macular cysts in the outer and inner nuclear layers, without macular edema.

\subsection{FAF}

Table 4 shows abnormal patterns observed in BAF and IRAF, illustrated in Figure 3.

BAF revealed abnormalities either limited to the macular area $(31 \%)$ or extended to the peripheral retina (68\%), and 6 distinct patterns were identified: discrete foveal abnormalities; macular hypo-autofluorescent (hypoAF) area surrounded, or not, by a ring of hyper-autofluorescence (hyperAF) or macular hypoAF spots sparing the peripheral retina; macular hypoAF area associated with hypoAF spots or "speckled" pattern in the peripheral retina; and extensive and confluent hypoAF patches associated, or not, with a "speckled" pattern.

A macular hyperAF ring was observed in $23 \%$ of patients, which included the optic nerve in $7 \%$ of cases. Among the 38 patients with extensive BAF abnormalities, $16 \%(6 / 38)$ revealed a peripapillary sparing. 
Table 4. BAF/IRAF abnormalities.

\begin{tabular}{|c|c|c|c|}
\hline $\begin{array}{l}\text { "BAF" Autofluorescence } \\
\text { (N = 56 Patients) }\end{array}$ & & $\begin{array}{l}\text { “IRAF" Autofluorescence } \\
\text { (N = } 52 \text { Patients) }\end{array}$ & \\
\hline Macular abnormalities & & Macular abnormalities & \\
\hline Minimal alterations, $\mathrm{n}(\%)$ & $6(10,5)$ & Minimal alterations, $\mathrm{n}(\%)$ & $6(11,5)$ \\
\hline Loss of foveal hypoAF, n (\%) & $1(2)$ & Loss of foveal hyperAF, $\mathrm{n}(\%)$ & $1(2)$ \\
\hline Foveal hyperAF, $\mathrm{n}(\%)$ & $2(3,5)$ & Foveal hypoAF, n (\%) & $3(5,5)$ \\
\hline Perifoveal hyperAF, n (\%) & $3(5)$ & Perifoveal hypoAF, n (\%) & $2(4)$ \\
\hline Macular hypoAF, n (\%) & $11(19,5)$ & Macular hypoAF, n (\%) & $16(30,5)$ \\
\hline Macular hypoAF spots, $\mathrm{n}(\%)$ & $1(2)$ & Macular hypoAF spots, n (\%) & $1(2)$ \\
\hline Diffuse retinal abnormalities & & Diffuse retinal abnormalities & \\
\hline $\begin{array}{c}\text { Macular hypoAF }+ \text { peripheral hypoAF } \\
\text { spots, } n(\%)\end{array}$ & $20(36)$ & $\begin{array}{c}\text { Macular hypoAF + peripheral hypoAF } \\
\text { spots, } n(\%)\end{array}$ & $13(25)$ \\
\hline $\begin{array}{l}\text { Macular hypoAF + peripheral } \\
\text { "speckled" aspect, } \mathrm{n}(\%)\end{array}$ & $5(9)$ & Macular + peripheral hypoAF, n (\%) & $16(31)$ \\
\hline $\begin{array}{c}\text { Macular hypoAF + peripheral confluent } \\
\text { hypoAF patches, } \mathrm{n}(\%)\end{array}$ & $13(23)$ & & \\
\hline without "speckled" aspect, n (\%) & $6(11)$ & & \\
\hline with "speckled" aspect, n (\%) & $7(12)$ & & \\
\hline $\begin{array}{l}\text { HyperAF ring } \\
\text { macular, } \mathrm{n}(\%)\end{array}$ & $9(16)$ & $\begin{array}{l}\text { HyperAF ring } \\
\text { macular, } \mathrm{n}(\%)\end{array}$ & $9(17)$ \\
\hline macular including the optic nerve, $\mathrm{n}(\%)$ & $4(7)$ & macular including the optic nerve, $\mathrm{n}(\%)$ & $3(6)$ \\
\hline Peripapillary sparing, $\mathrm{n}(\%), \mathrm{N}=38$ & $6(16)$ & Peripapillary sparing, $\mathrm{n}(\%), \mathrm{N}=29$ & $6(21)$ \\
\hline
\end{tabular}
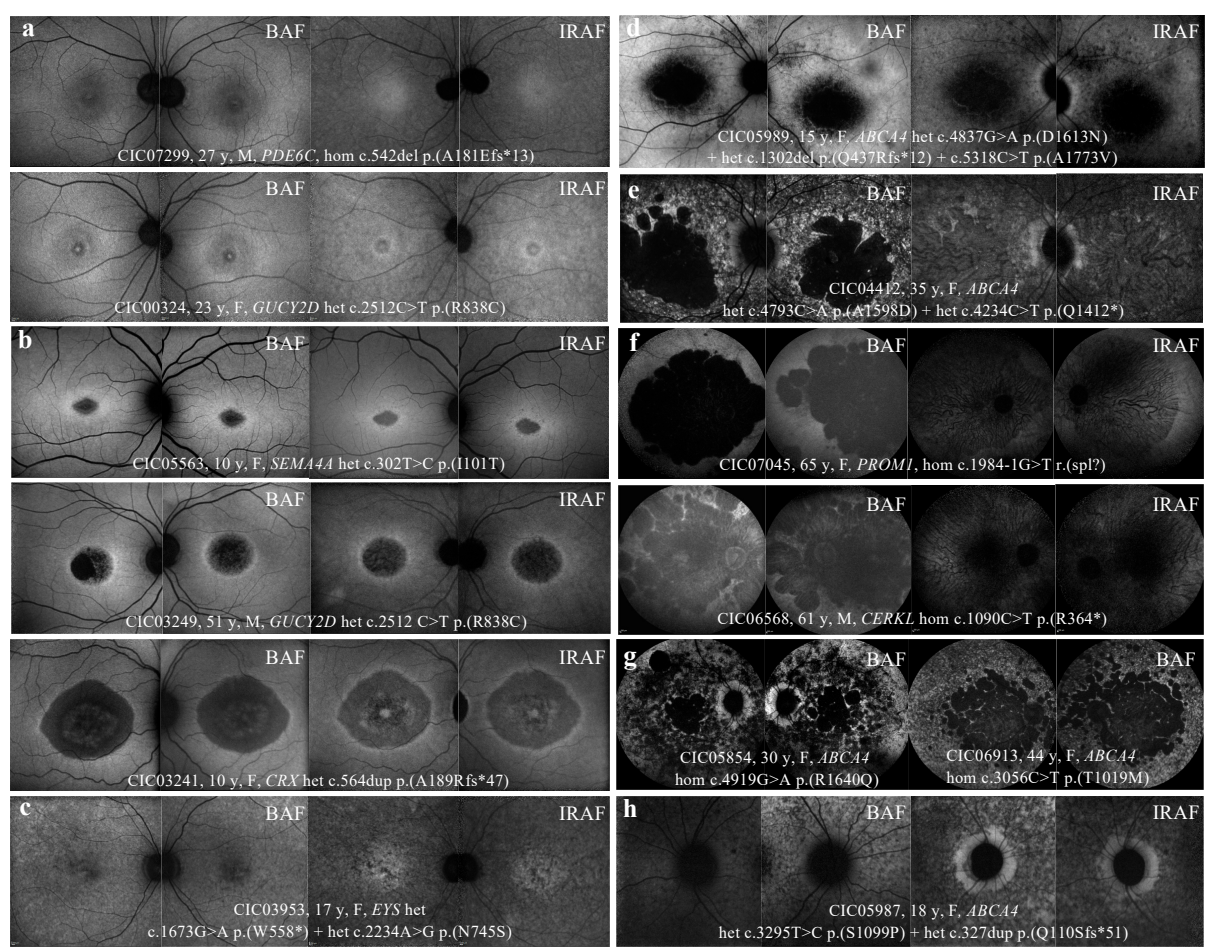

Figure 3. FAF and IRAF patterns observed in COD/CORD patients of the cohort. (a) Foveal and perifoveal hyperAF in BAF; foveal and perifoveal hypoAF in IRAF. (b) Macular hypoAF surrounded by a hyperAF ring in BAF and IRAF. (c) Macular hypoAF spots in BAF and IRAF. (d) Macular hypoAF associated with peripheral hypoAF spots in BAF and IRAF. (e) Macular hypoAF associated with peripheral "speckled" aspect (alternating hypoAF and hyperAF spots) in BAF and confluent hypoAF spots in IRAF. (f) Confluent hypoAF areas, involving the optic disc and extending beyond the vascular arcades. (g) Extensive and confluent hypoAF areas with a "speckled" aspect, associated (left) or not (right) with peripapillary sparing. (h) Sparing of peripapillary autofluorescence, more pronounced in IRAF than in BAF in this case. HypoAF: hypo-autofluorescence/hypo-autofluorescent; HyperAF: hyper-autofluorescence/hyper-autofluorescent; BAF: blue autofluorescence; IRAF: infrared autofluorescence. 
IRAF revealed abnormalities either limited to the macular area (44\%) or extended to the peripheral retina (56\%), and 5 distinct patterns were identified: discrete foveal abnormalities, macular hypoAF area or macular hypoAF spots sparing the peripheral retina, macular hypoAF area associated with hypoAF spots in the peripheral retina, and extensive macular and peripheral hypoAF.

Among the 29 patients with extensive IRAF abnormalities, 6 (21\%) revealed a peripapillary sparing, which was also observed in BAF. The macular hyperAF ring was detected on both BAF and IRAF (excepted for 1 patient whose IRAF imaging was not performed).

Unlike BAF imaging, the "speckled" pattern was not observed with IRAF in this cohort, and this pattern in BAF corresponded to confluent hypoAF areas in IRAF.

\subsection{Genotype Analysis with Respect to Structural Abnormalities}

Figure 4 shows the profile of mutated genes for each feature observed on retinophotography, SD-OCT, and FAF.
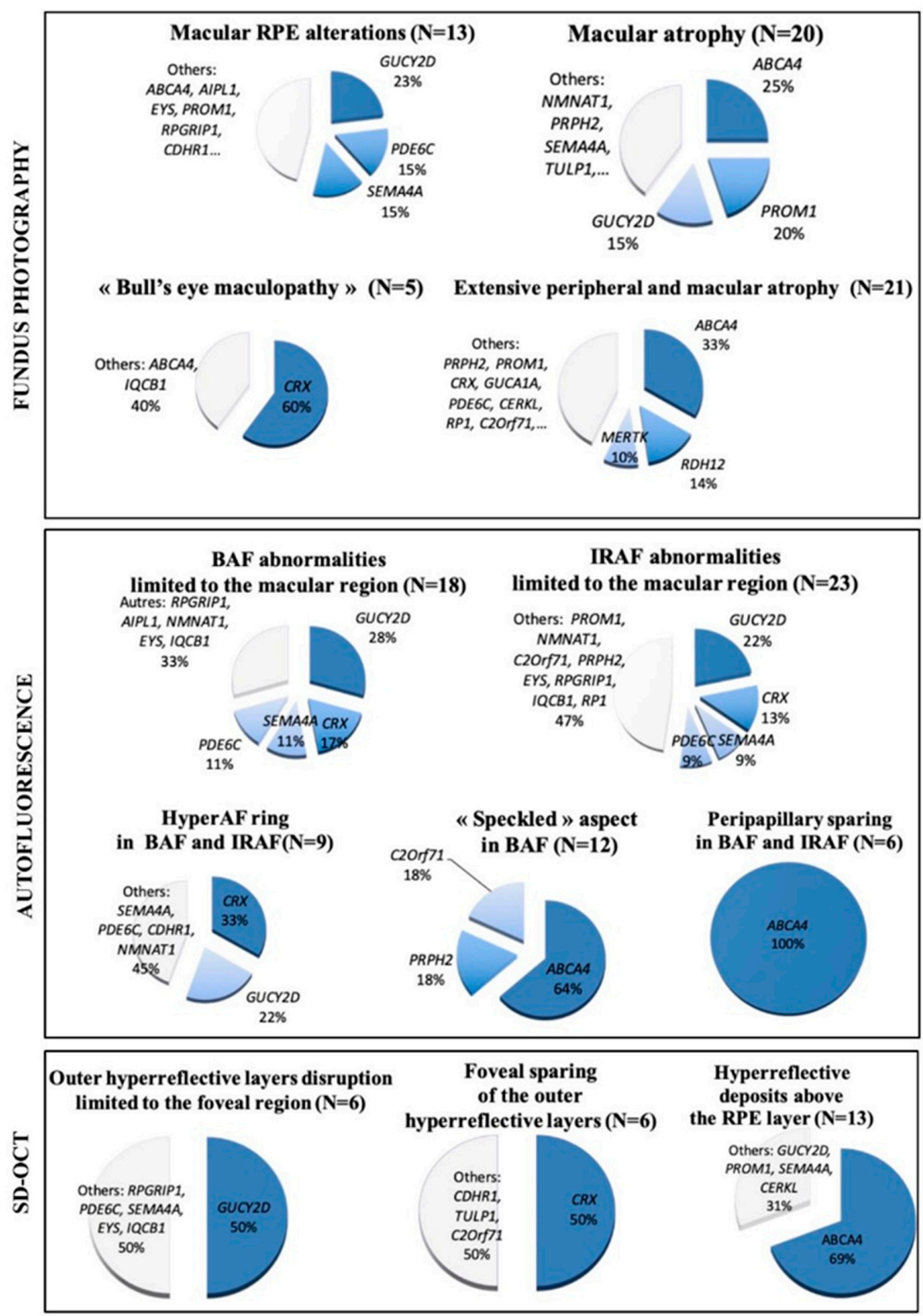

Figure 4. Profile of mutated genes for each feature observed on retinophotography, fundus autofluorescence, and spectral domain OCT. 
On SD-OCT, focal retrofoveal interruption of the outer retinal layers was more commonly observed in patients with GUCY2D mutations (50\%), whereas foveal sparing of the outer retinal layers was mainly associated with $C R X$ mutations (50\%). Among patients with hyper-reflective deposits above the RPE, $69 \%$ had $A B C A 4$.

Regarding FAF, a ring of increased AF was mainly observed in patients with CRX and GUCY2D mutations ( $33 \%$ and $22 \%$ of cases, respectively). The "speckled" AF was present in patients with mutations in 3 different genes ( $A B C A 464 \%$; $C 2 O r f 71$ and $P R P H 2,18 \%$ each). In addition, a peripapillary sparing was only found in patients with $A B C A 4$ mutations. (Figure 5).

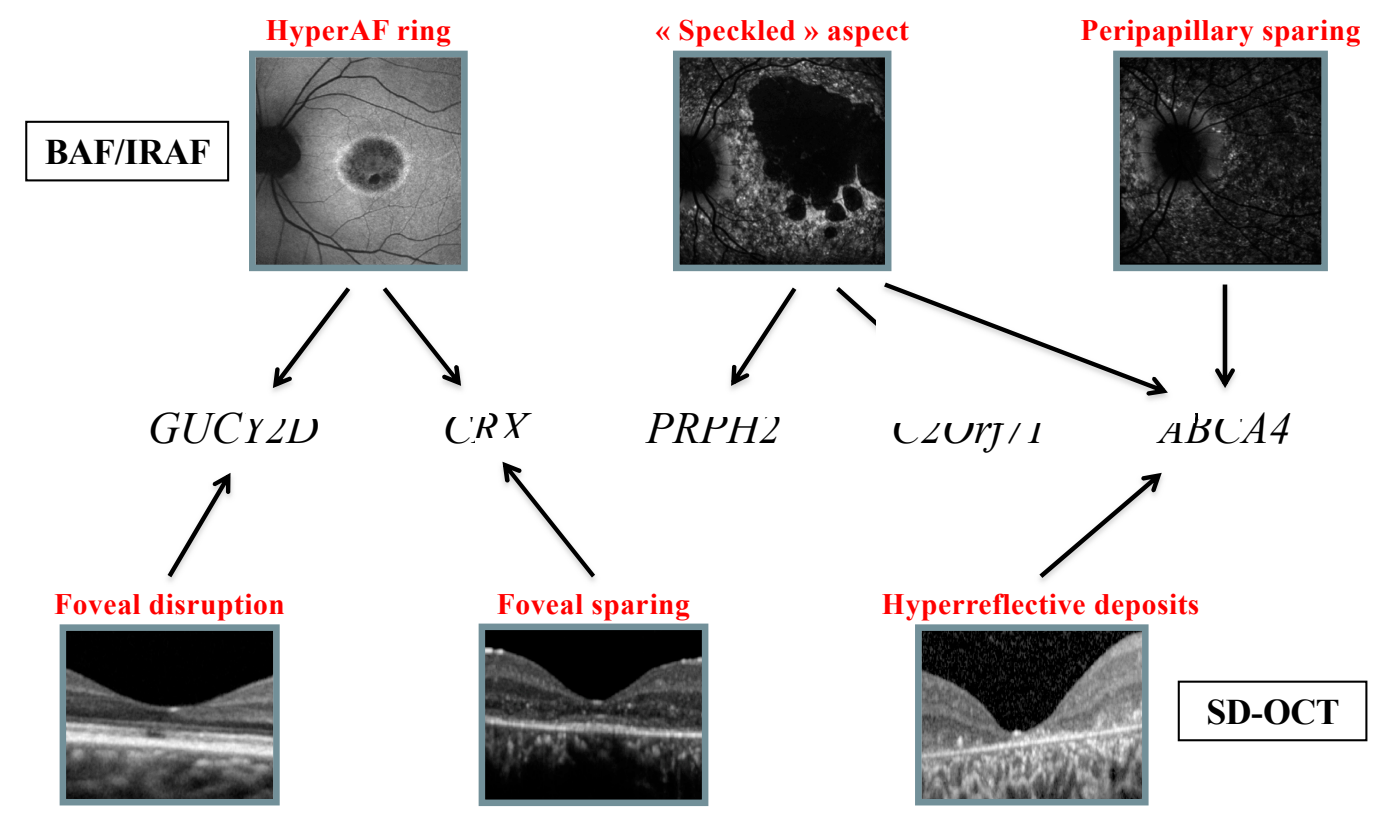

Figure 5. Decision tree showing clinical features of FAF and SD-OCT that may help to identify the causative genetic defect.

\section{Discussion}

We investigated a large series of CODs and CORDs patients, and we carefully evaluated their clinical characteristics using retinal imaging, which were further related to the genetic diagnosis.

\subsection{Retinophotography}

Fundus abnormalities ranged from discrete macular RPE alterations to extensive chorioretinal atrophy. (Figure 1) "Bull's eye" maculopathy, defined by perifoveal atrophy sparing the fovea, was observed only in $9 \%$ of cases, whereas macular atrophy was present in $34 \%$ of cases. These observations are similar to those reported by Thiadens et al. in a longitudinal study of 239 patients [2]. After 10 years of follow-up, 35\% of CODs and 58\% of CORDs showed macular atrophy, including "bull's eye" maculopathy.

In this cohort, fundus alterations limited to the macula were mainly observed in patients with ABCA4, GUCY2D, PROM1, CRX, SEMA4A, and PDE6C mutations. But these same mutated genes (except for GUCY2D) were also implicated in more severe clinical presentations with extensive retinal atrophy. These results outline the phenotypic variability associated with mutations in the same gene or even a same mutation. In a study including five families with autosomal dominant COD/CORDS cases carrying the same heterozygous p. (R373C) PROM1 exchange, phenotypes ranged from isolated macular dysfunction with "bull's eye" maculopathy to severe generalized cone-rod or rod-cone dysfunction, in patients from the same family [13]. In another study including 18 patients from 11 families, multimodal retinal imaging combined with electrophysiology identified 4 Leber congenital 
amaurosis (LCA), 2 retinitis pigmentosa (RP), 6 COD/CORDs, and 6 "atypical maculopathy" patients carrying the same heterozygous $C R X$ mutation [14].

In the present study, unlike mutations in $A B C A 4, P R O M 1$, or CRX, GUCY2D mutations were always associated with fundus alterations solely restricted to the macula (i.e., subtle changes or round atrophic lesion). No report of diffuse fundus alterations associated with GUCY2D mutations was found in the literature [15]. Thus, in this cohort, a GUCY2D mutation could be suspected in the case of restricted alterations to the macula on fundoscopy, but it is unlikely in case of peripheral damage.

\section{2. $S D-O C T$}

Outer hyper-reflective band abnormalities were more frequent in the foveal/perifoveal regions, where cone density is the highest. At a more advanced stage, the outer nuclear layer was atrophic with underlying choroidal hyper-reflectivity by window defect, limited to the macular area or extended to the peripheral retina. (Figure 2)

\subsubsection{Outer Hyperreflective Bands}

In a recent study, outer retinas of 12 CORDs patients with macular atrophy on fundoscopy were analyzed using SD-OCT [16]. Foveal IZ, EZ, and ELM were disrupted in 100\%, 92\%, and $83 \%$ of cases, respectively, whereas the RPE layer was always preserved. Outside the foveal region, IZ was absent in $100 \%$ of cases, whereas EZ was still present with decreased intensity. Our study also found a disruption of the outer hyperreflective bands, more frequently observed in the foveal and perifoveal regions, and was predominant on the IZ followed by EZ and ELM.

According to Lima et al., the lack of visibility of the IZ on SD-OCT could be linked to the loss or the shortening of the cone outer segments, reducing the possibility of proper interdigitation with the apical processes of the RPE cells [16]. Similarly, in COD animal models, there is a loss of the inner and outer cone segments, or there are alterations in the anatomic configuration of the apical processes $[17,18]$. This hypothesis is uncertain because there is a lack of correlative human histology. According to Inui et al., the loss of the IZ at the foveal region would be an early sign of cone-dominant photoreceptor impairment [19]. However, this feature is not specific to cone dystrophy, as it can be observed in patients with achromatopsia, high myopia, and age-related macular degeneration [20,21].

In this cohort, $50 \%$ of patients $(\mathrm{N}=6)$ with selective retrofoveal abnormalities (Figure 2a) revealed GUCY2D mutations, whereas $50 \%$ of patients $(\mathrm{N}=6)$ with foveal sparing (Figure $2 \mathrm{~g}$ ) carried CRX mutations.

\subsubsection{Hyporeflective Foveal Cavitation}

In three patients, a hyporeflective cavitation was observed in the foveal outer retina. (Figure 2b) This feature was previously described in COD/CORDs, congenital achromatopsia, and blue cone monochromacy [22]. It would be explained by the lack of cone outer segments with intact ELM [19,23]. According to Leng et al., foveal cavitation is a characteristic feature of cone dysfunction syndromes, without being specific to one disorder [24]. This feature seems to be associated with different genetic defects. In this cohort, it was observed in patients with GUCY2D, EYS, and SEMA4A mutations, whereas in the literature, it is described in patients with defects in GUCY2D, GUCA1A, and ABCA4 [15,24].

\subsubsection{Hyper-reflective Deposits above the RPE}

In $28 \%$ of patients, small hyperreflective dots or deposits were observed above the RPE, predominantly in the foveal and perifoveal regions. (Figure 2e) These deposits could represent lipofuscin or accumulated debris from photoreceptor outer segments that have not been properly phagocytosed by impaired RPE cells and/or microglial cells. This hypothesis lacks correlative human histology. In almost $70 \%$ of cases, this pattern was observed in patients with $A B C A 4$ mutations. This could be explained by the role of the resultant protein as an active transporter, therefore leading to retinoid accumulation above and inside RPE cells when mutated [25]. 


\subsubsection{Hyporeflective Macular Cysts}

Two patients with CRX and CRB1 mutations showed macular hyporeflective cysts on SD-OCT, at the level of the outer and inner nuclear layers. (Figure 2f) These cysts were not associated with macular edema and seemed to be degenerative within the atrophic retina. While hyporeflective cysts are commonly observed in RP, their association with COD/CORDs has not been reported so far $[16,26]$.

\subsection{Autofluorescence}

\subsubsection{BAF}

According to Wang et al., BAF imaging of COD/CORDs is highly heterogeneous and not specific to this pathology [27]. In this study, $6 \%$ of patients revealed an increase in foveal AF (loss of physiological foveal hypoAF or foveal hyperAF), which could reflect cone-RPE dysfunction. However, most of the patients showed macular or diffuse hypoAF, related to irreversible degeneration of photoreceptor and RPE cells. A recent study correlated the surface of BAF abnormalities using ultrawide field imaging with functional data (visual acuity, ERG, visual field). The authors showed that the extent of abnormal BAF was directly correlated to the severity of functional impairment [28].

In this cohort, patients with BAF abnormalities restricted to the macular region carried GUCY2D, $C R X, P D E 6 C$, and SEMA4A mutations. For some patients with ABCA4 and PROM1 mutations, abnormalities were more extensive in BAF than expected on fundoscopy. This observation outlines the fact that BAF imaging is more sensitive than retinophotography for the evaluation of structural impairment [28]. Gelman et al. recently showed that BAF features in Stargardt were able to discriminate Stargardt group 1 from group 2 as a functional correlate [29].

\subsubsection{HyperAF Ring}

In almost $25 \%$ of patients, macular hypoAF was surrounded by a ring of hyperAF. (Figure 3b) This feature is not specific to COD/CORDs, as it can be observed in other inherited retinal dystrophies, particularly in RP (59-94\% of cases) [30,31]. It is reported to reflect the transition between abnormal and normal retina. However, in contrast to RP, in COD/CORDs, the outer retina outside the ring is well-preserved, whereas it is atrophic within the ring. The hyperAF may suggest lipofuscin accumulation secondary to an increased rate of photoreceptor outer segment phagocytosis, with a direct toxicity on photoreceptor and RPE cells [32]. It could also be due to a window defect on RPE autofluorescence secondary to the lack of outer retinal layers. A correlation between SD-OCT and BAF would document the later hypothesis.

In the cohort, the hyperAF ring was observed in patients with CRX or GUCY2D mutations in $50 \%$ of cases, which is consistent with literature $[14,33]$. Associations with GUCA1A mutations have also been reported, but in our cohort, the only patient with a mutation on this gene revealed an extensive retinal atrophy. This phenotype is much more severe than usually reported in the literature in the case of mutations in this gene [15].

Thirty percent of patients, carrying mutations in SEMA4A, AIPLI, NMNAT1, or RDH12, displayed a hyperAF ring surrounding the optic nerve. This feature is also reported with $X$-linked retinal dystrophies in association with mutations in RPGR [3]. These patients were not included in the present study, as explained earlier [12].

\subsection{3. "Speckled" Pattern}

A "speckled" or "mottled" pattern was observed in $20 \%$ of patients, either in the macular region or extending beyond the vascular arcades. (Figure $3 \mathrm{e}, \mathrm{g}$ ) This feature with alternating hyperAF or hypoAF spots could correspond with co-existing window defects on RPE AF, lipofuscin deposits, and RPE atrophy [34-36]. This "speckled" feature is known to be associated with ABCA4 and PRPH2 mutations [3,34]. In this study, it was also observed in patients with mutations of three different genes: ABCA4 (64\%), PRPH2 (18\%), and also C2Orf71 (18\%). However, detailed semiologic observation 
revealed different features for each gene. (Figure 6) Patients with PRPH2 mutations led to larger, coarser, and less numerous hyperAF spots, with a reticular pattern, surrounding macula and the optic nerve (Figure 6a). For patients with $A B C A 4$ mutations, hypoAF and hyperAF spots were much more numerous and widespread, sparing classically the peripapillary region (Figure 6b). Finally, spots observed in patients with C2Orf71 mutations were smaller, leading to a granular pattern, extending beyond the vascular arcades without peripapillary sparing (Figure 6c). Such associations need to be confirmed by statistical analysis in a larger-scale study.

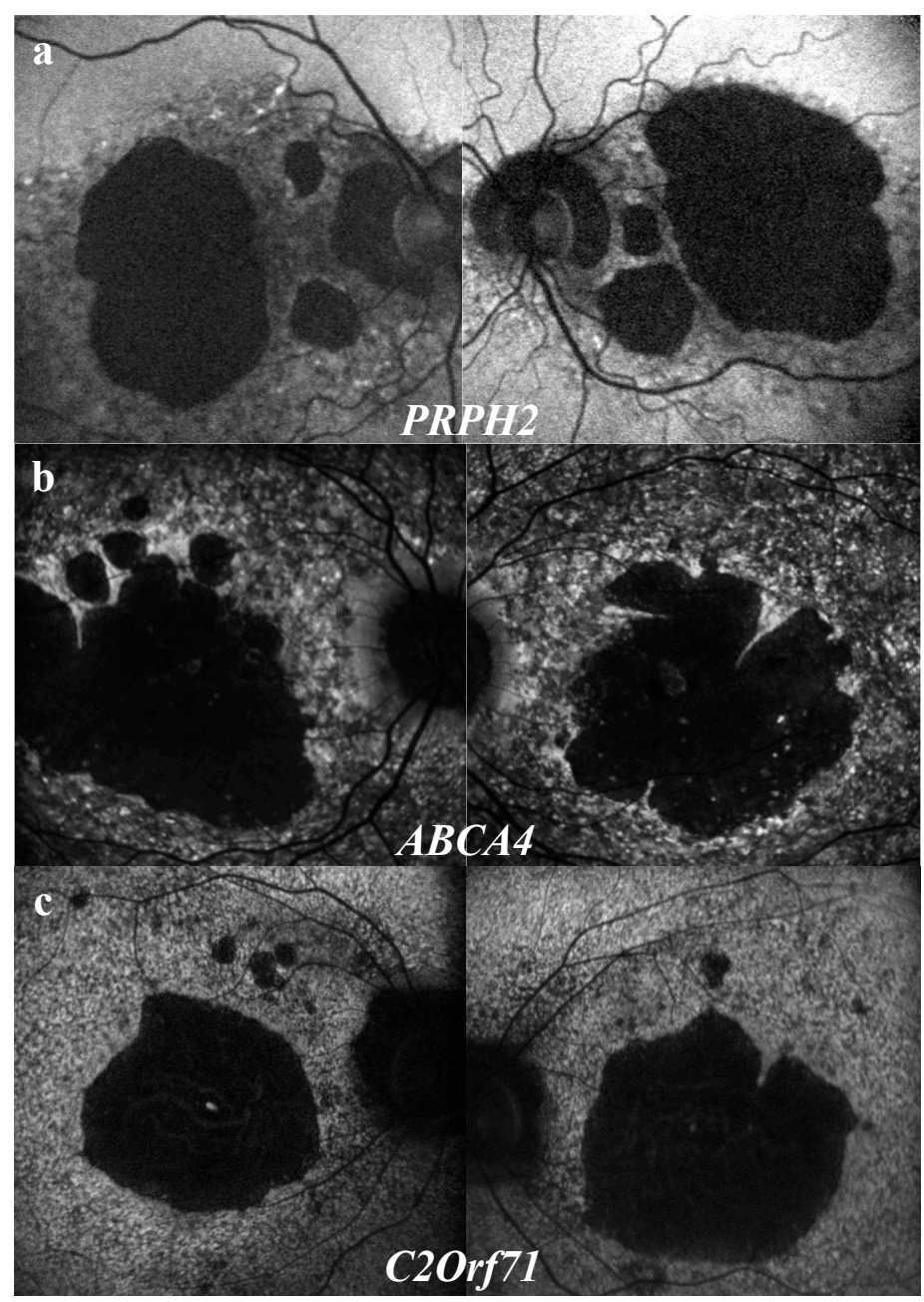

Figure 6. Characteristic features of the "speckled" aspect depending on the gene defect. (a) PRPH2 mutations: hyperAF spots are larger and less numerous, with reticular aspect, surrounding macular atrophy and the optic nerve. (b) $A B C A 4$ mutations: hyperAF spots are more numerous and widespread, sparing classically the peripapillary region. (c) C2Orf71 mutations: hyperAF are smaller, leading to a granular aspect, extending beyond the vascular arcades without peripapillary sparing.

\subsubsection{Peripapillary Sparing}

Sparing of the peripapillary AF was classically considered as pathognomonic and constant in $A B C A 4$-related diseases, even at the late stages with extensive retinal atrophy [36]. Recent studies showed that, although being specific, peripapillary sparing is not constant [37-40]. (Figure 3g,h)

A retrospective study including 32 patients with Stargardt groups 1, 2, and 3, according to the functional classification, showed the absence of peripapillary sparing in $6.7 \%, 100 \%$, and $90 \%$ of cases, respectively [37]. These results were probably overestimated because only one heterozygous $A B C A 4$ variant was necessary for the inclusion in the study, suggesting that $A B C A 4$ mutations may not have been the gene defect for some of the patients. In our study, peripapillary sparing was exclusively 
observed in patients carrying homozygous or compound heterozygous $A B C A 4$ mutations. However, it was observed in only $40 \%$ of $A B C A 4$-mutated patients with diffuse BAF abnormalities. Cideciyan et al. hypothesized that in the peripapillary region, turn-over of photoreceptor outer segments is reduced, with an optimized photoreceptor/RPE cells ratio explaining AF sparing. Of note, in MERTK-related diseases, characterized by outer segment phagocytic defects, there are widespread severe retinal abnormalities with no peripapillary sparing [41]. Another hypothesis would be the protective effect of the thickened retinal nerve fibers in this particular region towards oxidative stress and lipofuscin accumulation secondary to light exposure [36].

\subsection{IRAF}

IRAF imaging documents the distribution of melanin and melanolipofusin granules within RPE cells, as well as melanin within choroidal melanocytes [42]. In our study, all patients showed hypoAF in IRAF, with various patterns, limited to the macular region (44\%) or extended to the peripheral retina (56\%). Reduced IRAF could be explained by several mechanisms: posterior displacement of melanin granules secondary to lipofuscin accumulation in RPE cells, alteration of the RPE cell phagocytic activity, or loss of RPE cells [42].

No patient from the cohort revealed any increased IRAF or "speckled" aspect in IRAF. HyperAF spots in BAF appeared as hypoAF in IRAF in all patients (Figure 3e). In a study including 16 patients with $A B C A 4$-related retinal dystrophies, most of the patients (9/16) also revealed reduced IRAF, whereas for the other patients (4/16), a few small hyperAF dots in IRAF corresponding to hyperAF dots in BAF were observed [34]. Increased IRAF could be explained by apical displacement of melanin granules secondary to lipofuscin accumulation in RPE cells or melanin/melanolipofuscin accumulation secondary to increased RPE cell phagocytic activity [42].

Peripapillary preservation of IRAF was present in all six patients with peripapillary preservation of BAF (Figure 3h). Kellner et al. also found peripapillary sparing in 4/16 patients in both BAF and IRAF imaging [34]. These observations suggest a good correlation between BAF and IRAF imaging for the detection of peripapillary sparing.

\section{Patients and Methods}

\subsection{Study Population}

In a previous study [12], targeted NGS using a panel of 123 genes implicated in inherited retinal diseases (IRDs) was applied to 95 genetically unrelated ad and ar cone and cone-rod dystrophy cases, based on functional abnormalities, leading to the identification of the underlying genetic defects in $62.1 \%$ (59/95) of cases. Among the resolved cases, 58 subjects were selected for structural abnormalities analysis.

\subsection{Clinical Examination}

Each patient underwent full ophthalmic examination, as described earlier [43]. Clinical assessment was completed by retinophotography (CR1, Canon, Tokyo, Japan), spectral-domain optical coherence tomography (SD-OCT), and short wavelength (i.e., blue BAF) and near-infrared (IRAF) fundus autofluorescence imaging (FAF) (Spectralis ${ }^{\circledR}$ OCT and HRAII ${ }^{\circledR}$, Heidelberg Engineering, Dossenheim, Germany, respectively). Outer hyper-reflective bands were analyzed, including the external limiting membrane (ELM), the ellipsoid zone (EZ), the interdigitation zone (IZ), and the retinal pigment epithelium (RPE) [44,45]. The inner retina was further analyzed.

The study protocol adhered to the tenets of the Declaration of Helsinki and was approved by the local ethics committee (CPP, Comité de Protection des Personnes Ile de France V). 


\section{Conclusions}

This study outlines the high phenotypic and genetic heterogeneity of these rare diseases with a small sample size for each genotype. For this reason, we were not able to perform statistical association/correlation analysis. However, we attempted to draw schematic orientations only applicable to our cohort, based on retinal imaging abnormalities and genetic results. A larger study with a control group is necessary to extract statistically clinical patterns that may help in selecting pathogenic variants generated by high-throughput sequencing in our clinical practice. Second, we performed a cross-sectional study and did not correlate our findings to the disease stage. Longitudinal follow-up on a larger group of patients will help refine the identified correlations.

In conclusion, there is a need for the best genetic and phenotypic characterization of IRDs, applying, for instance, multimodal retinal imaging to identify specific phenotype-genotype correlations in order to improve diagnosis, management, genetic counseling, and patient information regarding the prognosis of IRDs. Furthermore, with the recent development of new therapeutic approaches, these results will also allow the clinician to guide therapeutic choices and establish clinical outcomes to monitor treatment efficacy.

Author Contributions: Conceptualization, E.B.-S., C.Z. and I.A.; methodology, C.Z. and I.A.; software, E.B.-S. and S.E.S.; validation, S.E.S., V.D., C.C., A.A., C.M., and F.B.; formal analysis, E.B.-S. and S.E.S.; investigation, S.E.S., V.D., C.C., A.A., C.M., F.B., J.-P.S., and M.L.; resources, E.B.-S.; data curation, E.B.-S.; writing-original draft preparation, E.B.-S.; writing-review and editing, S.M.-S., E.B.-S., C.Z., and I.A.; visualization, E.B.-S.; supervision, C.Z., I.A., and J.-A.S.; project administration, C.Z. and I.A.; funding acquisition, C.Z., I.A., and J.-A.S.

Funding: This work was supported by Foundation Fighting Blindness (FFB) [CD-CL-0808-0466-CHNO] (IA) and FFB center, [FFB grantC-GE-0912-0601-INSERM02], Prix de la Fondation de l'OEil (IA), Prix Berthe Fouassier Fondation de France (EBS), and by the French State program "Investissements d'Avenir" managed by the Agence Nationale de la Recherche [LIFESENSES: ANR-10-LABX-65].

Acknowledgments: The authors are grateful to patients and family members described in this study and clinical staff for their help in clinical data and DNA collection. DNA samples included in this study originated from NeuroSensCol DNA bank, from NeuroSensCol** (PI: JA Sahel, coPI I Audo, partner with CHNO des Quinze-Vingts, Inserm and CNRS).

Conflicts of Interest: No conflicting relationships exist for any author.

$\begin{array}{ll}\text { Abbreviations } & \\ \text { COD/CORDs } & \text { Cone/cone-rod dystrophies } \\ \text { NGS } & \text { Next Generation Sequencing } \\ \text { SD-OCT } & \text { Spectral-Domain Optical Coherence Tomography } \\ \text { BAF/IRAF } & \text { Short-wave length /infra-red fundus autofluorescence } \\ \text { IRDs } & \text { Inherited retinal disorders } \\ \text { ERG } & \text { Electroretinogram } \\ \text { RCD } & \text { Rod-cone dystrophy } \\ \text { Ar } & \text { Autosomal recessive } \\ \text { Ad } & \text { Autosomal dominant } \\ \text { Xl } & \text { X-linked } \\ \text { ABCA4 } & \text { ATP-binding cassette, sub-family A, member 4 } \\ \text { GUCY2D } & \text { Guanylate Cyclase 2D } \\ \text { RPGR } & \text { Retinitis Pigmentosa GTPase regulator } \\ \text { SD } & \text { Standard deviation } \\ \text { BCVA } & \text { Best corrected visual acuity } \\ \text { ETDRS } & \text { Early Treatment Diabetic Retinopathy Study } \\ \text { RP } & \text { Retinitis Pigmentosa } \\ \text { MD } & \text { Macular Dystrophy } \\ \text { LCA } & \text { Leber Congenital Amaurosis }\end{array}$


RPE Retinal Pigment Epithelium

ELM External limiting membrane

EZ Ellipsoid zone

IZ Interdigitation zone

HypoAF Hypo-autofluorescence/hypo-autofluorescent

HyperAF Hyper-autofluorescence/hyper-autofluorescent

\section{References}

1. Hamel, C.P. Cone rod dystrophies. Orphanet J. Rare Dis. 2007, 2, 7. [CrossRef] [PubMed]

2. Thiadens, A.A.H.J.; Phan, T.M.L.; Zekveld-Vroon, R.C.; Leroy, B.P.; van den Born, L.I.; Hoyng, C.B.; Klaver, C.C.; Writing committee for the cone disorders study group consortium; Roosing, S.; Pott, J.W.; et al. Clinical Course, Genetic Etiology, and Visual Outcome in Cone and Cone-Rod Dystrophy. Ophthalmol. 2012, 119, 819-826. [CrossRef] [PubMed]

3. Michaelides, M.; Hardcastle, A.J.; Hunt, D.M.; Moore, A.T. Progressive cone and cone-rod dystrophies: Phenotypes and underlying molecular genetic basis. Surv. Ophthalmol. 2006, 51, 232-258. [CrossRef] [PubMed]

4. Jalili, I.K.; Smith, N.J. A progressive cone-rod dystrophy and amelogenesis imperfecta: A new syndrome. J. Med. Genet. 1988, 25, 738-740. [CrossRef] [PubMed]

5. Aleman, T.S.; Cideciyan, A.V.; Volpe, N.J.; Stevanin, G.; Brice, A.; Jacobson, S.G. Spinocerebellar ataxia type 7 (SCA7) shows a cone-rod dystrophy phenotype. Exp. Eye Res. 2002, 74, 737-745. [CrossRef] [PubMed]

6. Roosing, S.; Thiadens, A.A.H.J.; Hoyng, C.B.; Klaver, C.C.W.; den Hollander, A.I.; Cremers, F.P.M. Causes and consequences of inherited cone disorders. Prog. Retin. Eye Res. 2014, 42, 1-26. [CrossRef] [PubMed]

7. Maugeri, A.; Klevering, B.J.; Rohrschneider, K.; Blankenagel, A.; Brunner, H.G.; Deutman, A.F.; Hoyng, C.B.; Cremers, F.P. Mutations in the ABCA4 (ABCR) gene are the major cause of autosomal recessive cone-rod dystrophy. Am. J. Hum. Genet. 2000, 67, 960-966. [CrossRef] [PubMed]

8. Kelsell, R.E.; Gregory-Evans, K.; Payne, A.M.; Perrault, I.; Kaplan, J.; Yang, R.B.; Garbers, D.L.; Bird, A.C.; Moore, A.T.; Hunt, D.M. Mutations in the retinal guanylate cyclase (RETGC-1) gene in dominant cone-rod dystrophy. Hum. Mol. Genet. 1998, 7, 1179-1184. [CrossRef] [PubMed]

9. Kitiratschky, V.B.D.; Wilke, R.; Renner, A.B.; Kellner, U.; Vadalà, M.; Birch, D.G.; Wissinger, B.; Zrenner, E.; Kohl, S. Mutation analysis identifies GUCY2D as the major gene responsible for autosomal dominant progressive cone degeneration. Invest. Ophthalmol. Vis. Sci. 2008, 49, 5015-5023. [CrossRef] [PubMed]

10. Demirci, F.Y.K.; Rigatti, B.W.; Wen, G.; Radak, A.L.; Mah, T.S.; Baic, C.L.; Traboulsi, E.I.; Alitalo, T.; Ramser, J.; Gorin, M.B. X-linked cone-rod dystrophy (locus COD1): Identification of mutations in RPGR exon ORF15. Am. J. Hum. Genet. 2002, 70, 1049-1053. [CrossRef] [PubMed]

11. Yang, Z.; Peachey, N.S.; Moshfeghi, D.M.; Thirumalaichary, S.; Chorich, L.; Shugart, Y.Y.; Fan, K.; Zhang, K. Mutations in the RPGR gene cause X-linked cone dystrophy. Hum. Mol. Genet. 2002, 11, 605-611. [CrossRef]

12. Boulanger-Scemama, E.; El Shamieh, S.; Démontant, V.; Condroyer, C.; Antonio, A.; Michiels, C.; Boyard, F.; Saraiva, J.-P.; Letexier, M.; Souied, E.; et al. Next-generation sequencing applied to a large French cone and cone-rod dystrophy cohort: Mutation spectrum and new genotype-phenotype correlation. Orphanet J. Rare Dis. 2015, 10, 85. [CrossRef] [PubMed]

13. Lima, L.H.; Sallum, J.M.F.; Spaide, R.F. Outer retina analysis by optical coherence tomography in cone-rod dystrophy patients. Retina 2013, 33, 1877-1880. [CrossRef] [PubMed]

14. Goldstein, O.; Mezey, J.G.; Boyko, A.R.; Gao, C.; Wang, W.; Bustamante, C.D.; Anguish, L.J.; Jordan, J.A.; Pearce-Kelling, S.E.; Aguirre, G.D.; et al. An ADAM9 mutation in canine cone-rod dystrophy 3 establishes homology with human cone-rod dystrophy 9. Mol. Vis. 2010, 16, 1549-1569. [PubMed]

15. Parry, D.A.; Toomes, C.; Bida, L.; Danciger, M.; Towns, K.V.; McKibbin, M.; Jacobson, S.G.; Logan, C.V.; Ali, M.; Bond, J.; et al. Loss of the metalloprotease ADAM9 leads to cone-rod dystrophy in humans and retinal degeneration in mice. Am. J. Hum. Genet. 2009, 84, 683-691. [CrossRef] [PubMed]

16. Inui, E.; Oishi, A.; Oishi, M.; Ogino, K.; Makiyama, Y.; Gotoh, N.; Kurimoto, M.; Yoshimura, N. Tomographic comparison of cone-rod and rod-cone retinal dystrophies. Graefes Arch. Clin. Exp. Ophthalmol. 2014, 252, 1065-1069. [CrossRef] 
17. Fujiwara, T.; Imamura, Y.; Margolis, R.; Slakter, J.S.; Spaide, R.F. Enhanced depth imaging optical coherence tomography of the choroid in highly myopic eyes. Am. J. Ophthalmol. 2009, 148, 445-450. [CrossRef]

18. Switzer, D.W.; Mendonça, L.S.; Saito, M.; Zweifel, S.A.; Spaide, R.F. Segregation of ophthalmoscopic characteristics according to choroidal thickness in patients with early age-related macular degeneration. Retina 2012, 32, 1265-1271. [CrossRef]

19. Barthelmes, D.; Sutter, F.K.; Kurz-Levin, M.M.; Bosch, M.M.; Helbig, H.; Niemeyer, G.; Fleischhauer, J.C. Quantitative analysis of OCT characteristics in patients with achromatopsia and blue-cone monochromatism. Invest. Ophthalmol. Vis. Sci. 2006, 47, 1161-1166. [CrossRef]

20. Thiadens, A.A.H.J.; Somervuo, V.; van den Born, L.I.; Roosing, S.; van Schooneveld, M.J.; Kuijpers, R.W.A.M.; van Moll-Ramirez, N.; Cremers, F.P.M.; Hoyng, C.B.; Klaver, C.C.W. Progressive loss of cones in achromatopsia: An imaging study using spectral-domain optical coherence tomography. Invest. Ophthalmol. Vis. Sci. 2010, 51, 5952-5957. [CrossRef]

21. Leng, T.; Marmor, M.F.; Kellner, U.; Thompson, D.A.; Renner, A.B.; Moore, W.; Sowden, J.C. Foveal cavitation as an optical coherence tomography finding in central cone dysfunction. Retina 2012, 32, 1411-1419. [CrossRef] [PubMed]

22. Duncker, T.; Tsang, S.H.; Lee, W.; Zernant, J.; Allikmets, R.; Delori, F.C.; Sparrow, J.R. Quantitative fundus autofluorescence distinguishes ABCA4-associated and non-ABCA4-associated bull's-eye maculopathy. Ophthalmology 2015, 122, 345-355. [CrossRef] [PubMed]

23. Salvatore, S.; Genead, M.A.; Fishman, G.A. The prevalence of macular cysts in patients with clinical cone-rod dystrophy determined by spectral-domain optical coherence tomography. Ophthalmic Genet. 2014, 35, 47-50. [CrossRef] [PubMed]

24. Wang, N.-K.; Chou, C.L.; Lima, L.H.; Cella, W.; Tosi, J.; Yannuzzi, L.A.; Tsang, S.H. Fundus autofluorescence in cone dystrophy. Doc. Ophthalmol. 2009, 119, 141-144. [CrossRef] [PubMed]

25. Oishi, M.; Oishi, A.; Ogino, K.; Makiyama, Y.; Gotoh, N.; Kurimoto, M.; Yoshimura, N. Wide-field fundus autofluorescence abnormalities and visual function in patients with cone and cone-rod dystrophies. Invest. Ophthalmol. Vis. Sci. 2014, 55, 3572-3577. [CrossRef]

26. Gelman, R.; Smith, R.T.; Tsang, S.H. Diagnostic accuracy evaluation of visual acuity and fundus autofluorescence macular geographic atrophy area for the discrimination of stargardt groups. Retina 2016, 36, 1596-1606. [CrossRef]

27. Robson, A.G.; Michaelides, M.; Saihan, Z.; Bird, A.C.; Webster, A.R.; Moore, A.T.; Fitzke, F.W.; Holder, G.E. Functional characteristics of patients with retinal dystrophy that manifest abnormal parafoveal annuli of high density fundus autofluorescence; A review and update. Doc. Ophthalmol. 2008, 116, 79-89. [CrossRef]

28. Lima, L.H.; Burke, T.; Greenstein, V.C.; Chou, C.L.; Cella, W.; Yannuzzi, L.A.; Tsang, S.H. Progressive constriction of the hyperautofluorescent ring in retinitis pigmentosa. Am. J. Ophthalmol. 2012, 153, 718-727.e2. [CrossRef]

29. Nong, E.; Lee, W.; Merriam, J.E.; Allikmets, R.; Tsang, S.H. Disease progression in autosomal dominant cone-rod dystrophy caused by a novel mutation (D100G) in the GUCA1A gene. Doc. Ophthalmol. 2014, 128, 59-67. [CrossRef]

30. Mukherjee, R.; Robson, A.G.; Holder, G.E.; Stockman, A.; Egan, C.A.; Moore, A.T.; Webster, A.R. A detailed phenotypic description of autosomal dominant cone dystrophy due to a de novo mutation in the GUCY2D gene. Eye 2014, 28, 481-487. [CrossRef]

31. Kellner, S.; Kellner, U.; Weber, B.H.F.; Fiebig, B.; Weinitz, S.; Ruether, K. Lipofuscin-and melanin-related fundus autofluorescence in patients with ABCA4-associated retinal dystrophies. Am. J. Ophthalmol. 2009, 147, 895-902.e1. [CrossRef] [PubMed]

32. Renner, A.B.; Fiebig, B.S.; Weber, B.H.F.; Wissinger, B.; Andreasson, S.; Gal, A.; Cropp, E.; Kohl, S.; Kellner, U. Phenotypic variability and long-term follow-up of patients with known and novel PRPH2/RDS gene mutations. Am. J. Ophthalmol. 2009, 147, 518-530.e1. [CrossRef] [PubMed]

33. Cideciyan, A.V.; Swider, M.; Aleman, T.S.; Sumaroka, A.; Schwartz, S.B.; Roman, M.I.; Milam, A.H.; Bennett, J.; Stone, E.M.; Jacobson, S.G. ABCA4-associated retinal degenerations spare structure and function of the human parapapillary retina. Invest. Ophthalmol. Vis. Sci. 2005, 46, 4739-4746. [CrossRef] [PubMed]

34. Burke, T.R.; Allikmets, R.; Smith, R.T.; Gouras, P.; Tsang, S.H. Loss of peripapillary sparing in non-group I Stargardt disease. Exp. Eye Res. 2010, 91, 592-600. [CrossRef] 
35. Burke, T.R.; Fishman, G.A.; Zernant, J.; Schubert, C.; Tsang, S.H.; Smith, R.T.; Ayyagari, R.; Koenekoop, R.K.; Umfress, A.; Ciccarelli, M.L.; et al. Retinal phenotypes in patients homozygous for the G1961E mutation in the ABCA4 gene. Invest. Ophthalmol. Vis. Sci. 2012, 53, 4458-4467. [CrossRef] [PubMed]

36. Hwang, J.C.; Zernant, J.; Allikmets, R.; Barile, G.R.; Chang, S.; Smith, R.T. Peripapillary atrophy in Stargardt disease. Retina 2009, 29, 181-186. [CrossRef] [PubMed]

37. Jayasundera, T.; Rhoades, W.; Branham, K.; Niziol, L.M.; Musch, D.C.; Heckenlively, J.R. Peripapillary dark choroid ring as a helpful diagnostic sign in advanced stargardt disease. Am. J. Ophthalmol. 2010, 149, 656-660.e2. [CrossRef] [PubMed]

38. Tschernutter, M.; Jenkins, S.A.; Waseem, N.H.; Saihan, Z.; Holder, G.E.; Bird, A.C.; Bhattacharya, S.S.; Ali, R.R.; Webster, A.R. Clinical characterisation of a family with retinal dystrophy caused by mutation in the Mertk gene. Br. J. Ophthalmol. 2006, 90, 718-723. [CrossRef] [PubMed]

39. Kellner, U.; Kellner, S.; Weinitz, S. Fundus autofluorescence (488 NM) and near-infrared autofluorescence (787 NM) visualize different retinal pigment epithelium alterations in patients with age-related macular degeneration. Retina 2010, 30, 6-15. [CrossRef]

40. Audo, I.; Sahel, J.-A.; Mohand-Saïd, S.; Lancelot, M.-E.; Antonio, A.; Moskova-Doumanova, V.; Nandrot, E.F.; Doumanov, J.; Barragan, I.; Antinolo, G.; et al. EYS is a major gene for rod-cone dystrophies in France. Hum. Mutat. 2010, 31, E1406-E1435. [CrossRef] [PubMed]

41. Spaide, R.F. Questioning optical coherence tomography. Ophthalmology 2012, 119, 2203-2204.e1. [CrossRef] [PubMed]

42. Spaide, R.F.; Curcio, C.A. Anatomical correlates to the bands seen in the outer retina by optical coherence tomography: Literature review and model. Retina 2011, 31, 1609-1619. [CrossRef] [PubMed]

43. Michaelides, M.; Gaillard, M.-C.; Escher, P.; Tiab, L.; Bedell, M.; Borruat, F.-X.; Barthelmes, D.; Carmona, R.; Zhang, K.; White, E.; et al. The PROM1 mutation p.R373C causes an autosomal dominant bull's eye maculopathy associated with rod, rod-cone, and macular dystrophy. Invest. Ophthalmol. Vis. Sci. 2010, 51, 4771-4780. [CrossRef] [PubMed]

44. Hull, S.; Arno, G.; Plagnol, V.; Chamney, S.; Russell-Eggitt, I.; Thompson, D.; Ramsden, S.C.; Black, G.C.; Robson, A.G.; Holder, G.E.; et al. The phenotypic variability of retinal dystrophies associated with mutations in CRX, with report of a novel macular dystrophy phenotype. Invest. Ophthalmol. Vis. Sci. 2014, 55, 6934-6944. [CrossRef] [PubMed]

45. Zobor, D.; Zrenner, E.; Wissinger, B.; Kohl, S.; Jägle, H. GUCY2D- or GUCA1A-related autosomal dominant cone-rod dystrophy: Is there a phenotypic difference? Retina 2014, 34, 1576-1587. [CrossRef] [PubMed] 